\title{
Queixas e diagnósticos relacionados ao trabalho em agroindústrias do oeste de Santa Catarina - Brasil
}

Márcia Luíza Pit Dal Magro

mapit@unochapeco.edu.br

Universidade Comunitária da Região de Chapecó (UNOCHAPECÓ), Chapecó, Santa Catarina, Brasil.

\section{Maria Chalfin Coutinho} maria.chalfin@ufsc.br Universidade Comunitária da Região de Chapecó (UNOCHAPECÓ), Chapecó, Santa Catarina, Brasil.

Clarete Trzcinski

\section{clarete@unochapeco.edu.br}

Universidade Comunitária da Região de Chapecó (UNOCHAPECÓ), Chapecó, Santa Catarina, Brasil.

Cristiane Tonezer tonezer@unochapeco.edu.br Universidade Comunitária da Região de Chapecó (UNOCHAPECÓ), Chapecó, Santa Catarina, Brasil.

\begin{abstract}
RESUMO
As indústrias de abate e processamento de carnes da região oeste de Santa Catarina são importantes para o setor econômico brasileiro, especialmente na produção e exportação de carne de aves. O município de Chapecó ocupa lugar de destaque nesse contexto, tendo em vista que é considerado um dos maiores centros agroindustriais do país, tendo aproximadamente $18 \%$ da força de trabalho ocupada neste setor. Porém, destaca-se as difíceis condições de trabalho nessas indústrias que são amplamente associadas à agravos em saúde, como as Lesões por Esforços Repetitivos (LER). Este artigo traçou como objetivo geral compreender as principais queixas e diagnósticos em saúde dos trabalhadores das indústrias de abate e processamento de carnes do oeste do estado de Santa Catarina Brasil. O processo investigativo se deu a partir da pesquisa qualitativa e utilizou diferentes instrumentos: observação participante; entrevistas semiestruturadas e pesquisa documental. A análise das informações foi realizada com base na Grounded Theory. Como resultados encontraram-se queixas relacionadas ao trabalho de ordem física, psicológica e social. Quanto aos diagnósticos recebidos, estes são prioritariamente do grupo F, no qual se descrevem os transtornos mentais e comportamentais, do grupo $\mathrm{M}$, que diz respeito às doenças do sistema osteomuscular e do tecido conjuntivo e do grupo G, que representa as doenças do sistema nervoso.
\end{abstract}

PALAVRAS-CHAVE: Saúde do trabalhador. Queixas em saúde. LER/DORT. Agroindústrias. 


\section{INTRODUÇÃO}

A organização do trabalho nas indústrias de abate e processamento de carnes, está pautada no modelo taylorista fordista, apresentando também características do modelo japonês. As atividades nas linhas de produção do setor caracterizam-se por funções altamente rotinizadas e repetitivas, intenso ritmo de trabalho e inúmeras formas de vigilância e controle do trabalhador. Nesse contexto, observa-se nos últimos anos um processo de intensificação e prolongamento da jornada laboral, o que afeta a saúde dos trabalhadores do setor (DAL MAGRO et al, 2014).

Estas indústrias de alimentossão amplamente reconhecidas pelos altos índices de afastamento dos trabalhadores em função de agravos à saúde como indica os estudos de Sardáet al (2009) e da Procuradoria Regional do Trabalho (2013). Este cenário levou a criação em 2013 de Norma Regulamentadora específica para o setor. A (NR) 36tem como objetivo "[...] estabelecer os requisitos mínimos para a avaliação, controle e monitoramento dos riscos existentes nas atividades [...], de forma a garantir permanentemente a segurança, a saúde e a qualidade de vida no trabalho" (MINISTÉRIO DO TRABALO E EMPREGO, 2013).

Apensar dos avanços na construção de um marco regulatório para o campo da Saúde do Trabalhador nas últimas décadas, dos quais são exemplo a Política Nacional de Saúde do Trabalhador e da Trabalhadora (Brasil, 2012) e a criação do Nexo Técnico Epidemiológico Previdenciário (MACHADO; SORATTO; CODO, 2010),o poder econômico destas indústrias tem dificultado a implementação das ações de segurança e saúde do trabalhador (DAL MAGRO; COUTINHO; MORÉ, no prelo; DAL MAGRO; COUTINHO; MORÉ, 2013). Também continua sendo uma dificuldade dos profissionais de saúde, relacionar determinados agravos com o trabalho realizado, como acontece com os transtornos mentais e comportamentais (AMAZARRAY; CÂMARA; CARLOTTO, 2014).

Assim, conhecer as características das dificuldades em saúde que afetam os trabalhadores do setor pode ajudar no estabelecimento do nexo entre os agravos e o trabalho realizado, bem como subsidiar ações dos serviços de saúde que atendem estes trabalhadores usuários. Neste cenário, o objetivo da pesquisa ora apresentada foi compreender as principais queixas e diagnósticos em saúde dos trabalhadores das indústrias de abate e processamento de carnes do oeste do estado de Santa Catarina - Brasil ${ }^{1}$.

Cabe destacar a importância do setor agroindústria na região do estudo tendo em vista que o estado de Santa Catarina liderava, até 2008, a produção e exportação de aves no Brasil (RECHE; SUGAI, 2008), e Chapecó-SC, local em que foi desenvolvida a pesquisa, é considerado pelos autores um importante centro agroindustrial do país. Estemunicípio é sede de empresas líderes no mercado nacional de carne de aves e suínos, como Brasil Foods e Aurora Alimentos, e aproximadamente $18 \%$ da força de trabalho ocupada está empregada na indústria de abate e processamento de carnes (IBGE, 2009). No cenário nacional também se destaca a importância econômica do setor, tendo em vista que de acordo com Dalla Costa e Souza-Santos (2009) entre estas indústrias de alimentos está a maior empregadora do país.

${ }^{1}$ Este estudo traz parte dos resultados de pesquisa de tese de doutorado (DAL MAGRO, 2012). 
O estudo estrutura-se a partir desta introdução, após serão trazidas a metodologia e os resultados, este último dividido em duas etapas: a primeira relata as queixas em saúde relacionadas ao trabalho e a segunda o diagnóstico em saúde relacionado ao trabalho. As teorias existente acerca do assunto mesclam-se com os resultados. Por fim tecer-se-ão as considerações finais.

\section{METODOLOGIA}

Este estudo é de natureza qualitativa, sendo descritivo e exploratório. A pesquisa teve como cenário principal um serviço de atenção básica denominado Centro Integrado de Saúde da Família (CIS), localizado na região mais populosa do Município de Chapecó, no qual foi realizado o estudo, este centro estando próximo à três grandes agroindústrias. Assim, parte significativa dos usuários atendidos por esse serviço era composta por trabalhadores das fábricas que residiam no território de abrangência do Centro de Saúde. A pesquisa de campo ocorreu ao longo do ano de 2010.

$\mathrm{Na}$ ocasião da pesquisa, atuavam no CIS quatro equipes de saúde da família, cada uma composta por um médico, um enfermeiro e seis agentes comunitários de saúde (ACS). O referido CIS também era referência para outros centros de saúde da microrregião, dispondo de especialidades como ginecologia, pediatria, bem como atuava na realização de pequenas cirurgias. Anexo ao Centro de Saúde funcionava também o Serviço Municipal de Diagnósticos por Imagem que atende à rede básica, e o Pronto Atendimento (PA), que compreende o atendimento préhospitalar.

A pesquisa contou com dois grupos de participantes, sendo um deles constituído por dezessete trabalhadores das três grandes agroindústrias da região. Já o outro grupo era composto por catorze profissionais de saúde que atuavam na rede pública, ao qual se agregou também um ex-trabalhador da agroindústria que atuava em uma associação para vítimas de acidentes de trabalho.

Os instrumentos e técnicas de pesquisa foram a observação participante registrada emdiário de campo, entrevistas semiestruturadas realizadas com os trabalhadores das agroindústrias e profissionais de saúde, e pesquisa documental aos prontuários de saúde dos trabalhadores usuários, disponíveis no Centro Integrado de Saúde. As observações participantes ocorreram nas diferentes atividades do CIS como visitas domiciliares, reuniões da equipe de Estratégia de Saúde da Família, consultas médicas e atendimentos psicológicos. O estudo foi aprovado por comitê de ética de acordo com o que previa a resolução 196/1996 do Conselho Nacional de Saúde, vigente na ocasião do estudo.

A organização e análise das informações se deram com base na GroundedTheory, ou Teoria Fundamentada nos Dados (STRAUSS; CORBIN, 2008), dando origem a duas categorias de análise, sendo elas: queixas em saúde; Diagnósticos realizados. 


\section{QUEIXAS EM SAÚDE RELACIONADAS AO TRABALHO}

A palavra queixa é frequentemente utilizada no campo da saúde, para se referir às dificuldades que os usuários comunicam aos profissionais de saúde, no seu contato com os serviços. Nesse sentido, faz-se menção ao termo para falar de aspectos como a importância em se identificar as principais queixas em saúde e de acolher essas queixas, bem como de ouvir para além delas reconhecendo outros elementos importantes para o processo de saúde e doença do usuário, o que é preconizado por documentos da Política Nacional de Humanização (BRASIL, 2004a; BRASIL, 2004b; BRASIL, 2008b; BRASIL, 2009).

Na busca por uma definição desse conceito, a fim de utilizá-lo no presente estudo, buscou-se o dicionário, o qual define queixa como "reclamação fundada em prejuízo ou em ofensas recebidas com diminuição moral ou física de qualquer natureza. [...] Palavras de sentimento, de dor ou desgosto; lamentação. Causa de ressentimento. Exposição de sofrimentos; [...] choro, pranto" (GREGORIM, 2007). A partir dessa descrição, se observa que há semelhanças entre o uso corrente do termo no campo da saúde e a definição dele no sentido genérico.

A partir do exposto, o sentido da expressão queixas em saúde neste trabalho se refere não à doença em si, mas àquilo que o trabalhador expressa e/ou comunica sobre seu estado de saúde quando questionado em relação ao mesmo. Esta noção identifica, assim, experiências de mal estar ou desconforto dos sujeitos entrevistados, que têm no trabalho a sua origem ou que estabelece uma relação direta com ele.

Segue um quadro em que são apresentadas as queixas dos trabalhadores entrevistados, as quais foram organizadas em três grupos distintos, sendo eles: queixas físicas, queixas psicológicas e queixas sociais. Em relação a essa organização, cabe apontar que ela tem fins meramente didáticos, a fim de dar visibilidade aos diferentes campos que permeiam as dificuldades em saúde dos entrevistados. Nesse sentido, os grupos mencionados não podem ser analisados separadamente já que se implicam e condicionam reciprocamente.

Quadro 1: Queixas em saúde relacionadas ao trabalho

\begin{tabular}{|c|c|c|c|}
\hline \multirow[t]{2}{*}{ Trab. } & \multicolumn{3}{|c|}{ QUEIXAS EM SAÚDE RELACIONADAS AO TRABALHO } \\
\hline & Físicas & Psicológicas & Sociais \\
\hline 01 & $\begin{array}{c}\text { - Dores em uma das mãos e braço, } \\
\text { coluna cervical e cabeça, que } \\
\text { aumentam durante o repouso e à } \\
\text { noite; } \\
\text { - Limitação dos movimentos da } \\
\text { mão e punho; } \\
\text { - Formigamentos e dormência nas } \\
\text { mãos durante a noite; } \\
\text { - Presença de nódulo doloroso sob } \\
\text { a pele; } \\
\text { - Alterações do sono. }\end{array}$ & $\begin{array}{l}\text { - Sensação de } \\
\text { esgotamento } \\
\text { físico e } \\
\text { emocional. }\end{array}$ & $\begin{array}{l}\text { - Não poder trocar de } \\
\text { emprego devido ao } \\
\text { problema de saúde. }\end{array}$ \\
\hline 02 & $\begin{array}{l}\text { - Dores intensas e contínuas na } \\
\text { região da coluna cervical, em } \\
\text { ambos os braços e mãos. } \\
\text { - Perda e limitação dos }\end{array}$ & $\begin{array}{l}\text { - Ansiedade; } \\
\text { - Irritabilidade; } \\
\text { - Sentimento de } \\
\text { tristeza; }\end{array}$ & $\begin{array}{l}\text { - Não poder trocar de } \\
\text { emprego devido ao } \\
\text { problema de saúde; } \\
\text { - Limitação no }\end{array}$ \\
\hline
\end{tabular}




\begin{tabular}{|c|c|c|c|}
\hline & $\begin{array}{l}\text { movimentos dos braços e mãos; } \\
\text { - Formigamento e perda de força } \\
\text { nos braços e mãos; } \\
\text { - Aumento de peso; } \\
\text { - Alterações do sono. }\end{array}$ & $\begin{array}{l}\text { - Medo do } \\
\text { futuro. }\end{array}$ & $\begin{array}{l}\text { exercício nas } \\
\text { atividades cotidianas; } \\
\text { - Isolamento social. }\end{array}$ \\
\hline 03 & $\begin{array}{c}\text { - Dores intensas e contínuas nos } \\
\text { braços; } \\
\text { - Perda e limitação dos } \\
\text { movimentos dos braços. }\end{array}$ & - Irritabilidade. & $\begin{array}{c}\text { - Limitação no } \\
\text { exercício nas } \\
\text { atividades cotidianas. }\end{array}$ \\
\hline 04 & $\begin{array}{l}\text { - Dores em um dos braços e coluna } \\
\text { cervical; } \\
\text { - Inchaço na região do braço; } \\
\text { - Presença de nódulo doloroso sob } \\
\text { a pele. }\end{array}$ & - Irritabilidade. & \\
\hline 05 & $\begin{array}{l}\text { - Dores em uma das mãos, braço, } \\
\text { coluna cervical e perna. } \\
\text { - Inchaço e perda de força no braço } \\
\text { e mão; } \\
\text { - Perda e limitação dos } \\
\text { movimentos da mão e braço; } \\
\text { - Presença de nódulo doloroso sob } \\
\text { a pele; } \\
\text { - Perda da sensibilidade da mão; } \\
\text { - Aumento de peso; } \\
\text { - Alterações do sono. }\end{array}$ & $\begin{array}{l}\text { - Ansiedade; } \\
\text { - Irritabilidade; } \\
\text { - Sentimento de } \\
\text { tristeza; } \\
\text { - Medo do } \\
\text { futuro. }\end{array}$ & $\begin{array}{l}\text { - Limitação no } \\
\text { exercício nas } \\
\text { atividades cotidianas; } \\
\text { - Isolamento social; } \\
\text { - Conflitos familiares. }\end{array}$ \\
\hline 06 & $\begin{array}{l}\text { - Dores nos braços durante o } \\
\text { exercício do trabalho, que } \\
\text { diminuem no repouso; } \\
\text { - Formigamento das pernas; } \\
\text { - Alterações do sono. }\end{array}$ & - Ansiedade; & \\
\hline 07 & $\begin{array}{c}\text { - Dores nos dedos das mãos, } \\
\text { cotovelos, ombros e coluna cervical } \\
\text { que aumentam durante o repouso } \\
\text { e a noite; } \\
\text { - Inchaço e perda de força nos } \\
\text { braços; } \\
\text { - Limitação dos movimentos dos } \\
\text { braços e mãos; } \\
\text { - Sensação de dormência nos } \\
\text { braços; } \\
\text { - Alterações do sono. }\end{array}$ & $\begin{array}{l}\text { - Irritabilidade; } \\
\text { - Sentimento de } \\
\text { tristeza; } \\
\text { - Sensação de } \\
\text { esgotamento } \\
\text { físico e } \\
\text { emocional. }\end{array}$ & $\begin{array}{l}\text { - Isolamento social; } \\
\text { - Não poder trocar de } \\
\text { emprego devido ao } \\
\text { problema de saúde; } \\
\text { - Conflitos familiares. }\end{array}$ \\
\hline 08 & $\begin{array}{c}\text { - Dores intensas e contínuas em } \\
\text { um dos braços e mãos; } \\
\text { - Perda e limitação dos } \\
\text { movimentos dos braços e mãos; } \\
\text { - Sensação de ardência e coceira no } \\
\text { braço. } \\
\text { - Alterações do sono. }\end{array}$ & $\begin{array}{l}\text { - Ansiedade; } \\
\text { - Irritabilidade; } \\
\text { - Medo do } \\
\text { futuro. }\end{array}$ & $\begin{array}{c}\text { - Limitação no } \\
\text { exercício nas } \\
\text { atividades cotidianas; } \\
\text { - Não poder trocar de } \\
\text { emprego devido ao } \\
\text { problema de saúde. }\end{array}$ \\
\hline 09 & $\begin{array}{l}\text { - Dores na cabeça, região da mão, } \\
\text { pulso e ombro; } \\
\text { - Presença de nódulo doloroso sob } \\
\text { a pele; } \\
\text { - Aumento de peso. }\end{array}$ & $\begin{array}{l}\text { - Ansiedade; } \\
\text { - Irritabilidade; } \\
\text { - Sentimento de } \\
\text { tristeza; }\end{array}$ & $\begin{array}{l}\text { - Isolamento social; } \\
\text { - Conflitos familiares. }\end{array}$ \\
\hline 10 & $\begin{array}{l}\text { - Dores em um dos punhos, coluna } \\
\text { cervical e uma das pernas. }\end{array}$ & & $\begin{array}{l}\text { - Limitação no } \\
\text { exercício nas }\end{array}$ \\
\hline
\end{tabular}




\begin{tabular}{|c|c|c|c|}
\hline & & & $\begin{array}{l}\text { atividades cotidianas; } \\
\text { - Não poder trocar de } \\
\text { emprego devido ao } \\
\text { problema de saúde. }\end{array}$ \\
\hline 11 & $\begin{array}{l}\text { - Dores intensas e contínuas em } \\
\text { uma das mãos e braços. } \\
\text { - Perda de força e inchaço na } \\
\text { região do braço e mão; } \\
\text { - Formigamento, sensação de } \\
\text { ardência e dormência da mão; } \\
\text { - Perda e limitação dos } \\
\text { movimentos do braço e mão. }\end{array}$ & $\begin{array}{l}\text { - Irritabilidade; } \\
\text { - Sentimento de } \\
\text { tristeza; } \\
\text { - Medo do } \\
\text { futuro. }\end{array}$ & $\begin{array}{l}\text { - Limitação no } \\
\text { exercício nas } \\
\text { atividades cotidianas; }\end{array}$ \\
\hline 12 & $\begin{array}{l}\text { - Dores na região do punho que } \\
\text { aumentam durante o repouso e à } \\
\text { noite; } \\
\text { - Inchaço na região do punho; } \\
\text { - Perda e limitação dos } \\
\text { movimentos da mão e punho. }\end{array}$ & & \\
\hline 13 & $\begin{array}{l}\text { - Dores intensas e contínuas na } \\
\text { região do braço; } \\
\text { - Perda e limitação dos } \\
\text { movimentos do braço; } \\
\text { - Perda de peso. }\end{array}$ & $\begin{array}{l}\text { - Irritabilidade; } \\
\text { - Sentimento de } \\
\text { tristeza; }\end{array}$ & $\begin{array}{l}\text { - Isolamento social; } \\
\text { - Conflitos familiares; } \\
\text { - Limitação no } \\
\text { exercício nas } \\
\text { atividades cotidianas. }\end{array}$ \\
\hline 14 & $\begin{array}{l}\text { - Dores na região do braço, que } \\
\text { aumentam durante o repouso; } \\
\text { - Limitação de movimentos do } \\
\text { pulso e braço. }\end{array}$ & & \\
\hline 15 & $\begin{array}{l}\text { - Dores na região do pulso e cintura } \\
\text { pélvica; } \\
\text { - Sensação de queimação na região } \\
\text { do quadril; } \\
\text { - Perda e limitação de movimentos } \\
\text { da perna. }\end{array}$ & - Ansiedade. & \\
\hline 16 & $\begin{array}{l}\text { - Dores em ambos os braços e na } \\
\text { região lombar, que aumentam } \\
\text { durante o repouso, } \\
\text { - Formigamento na região dos } \\
\text { braços e mãos. }\end{array}$ & & $\begin{array}{l}\text { - Limitação no } \\
\text { exercício nas } \\
\text { atividades cotidianas. }\end{array}$ \\
\hline 17 & $\begin{array}{l}\text { - Dores na região da cintura } \\
\text { pélvica, especialmente para } \\
\text { caminhar e ficar de pé. }\end{array}$ & $\begin{array}{l}\text { - Irritabilidade; } \\
\text { - Sentimento de } \\
\text { tristeza. }\end{array}$ & $\begin{array}{l}\text { - Limitação no } \\
\text { exercício de } \\
\text { atividades cotidianas; } \\
\text { - Conflitos familiares; } \\
\text { - Isolamento social. }\end{array}$ \\
\hline
\end{tabular}

Em relação ao quadro apresentado, cabe apontar que ele representa sujeitos cujos tempos de trabalho nas agroindústrias e os tempos dos percursos pelos serviços de saúde são muito distintos. A idade desses participantes variava de uma idade mínima de vinte e quatro anos a uma idade máxima de quarenta e cinco anos, sendo que a idade média desses trabalhadores era de aproximadamente trinta e sete anos. Em relação ao tempo de vínculo empregatício desses trabalhadores com o setor agroindustrial, esse variava de um mínimo de seis meses a um máximo de vinte e cinco anos, sendo que o tempo médio de trabalho era de aproximadamente onze anos. Já em relação ao 
tempo de percurso pela rede de saúde em função das queixas, este variava de dois meses a quatorze anos.

Se realizada uma leitura vertical das colunas dispostas no quadro anterior, chama a atenção o fato de que apesar das singularidades que distinguem um caso de outro, é possível observar uma grande semelhança entre as queixas dos diferentes trabalhadores usuários, o que indica a sua origem comum. As queixas físicas dizem respeito às alterações e aos desconfortos nos membros superiores, mas também nos membros inferiores, compreendendo especialmente as dores osteomusculares, as quais são citadas por todos os trabalhadores entrevistados. Os entrevistados fazem menção a frequências e intensidades distintas dessas dores; no entanto, na maioria dos casos relatados elas se manifestam em mais de uma região do corpo, principalmente mãos, braços e coluna cervical. Em dezesseis dos casos, a menção a essas dores vai ao encontro do que Assunção e Vilela (2009) definem como dor crônica, que é aquela cuja duração é maior de três meses.

De acordo com Henriques et al (2015) a dor é um mecanismo adaptativo que caracteriza um dos '[...] principais sinais de alarme para proteção da vida e da integridade do organismo humano". No entanto, a dor crônica "[...] passa a ser uma percepção desestabilizadora, sem valor protetor ao indívíduo" (p. 690), estando associada a quadros de sofrimento que limitam e modificam o comportamento dos sujeitos.

O reconhecimento do início dos episódios dolorosos varia de um trabalhador para outro, sendo que a maioria (onze entrevistados) relatou que a dor que simboliza o início da dificuldade em saúde, iniciou com até cinco anos de trabalho. Nesse sentido, cinco trabalhadores entrevistados descreveram que as dificuldades em saúde iniciaram durante os seis primeiros meses de trabalho na linha de produção. Seis entrevistados mencionaram que as dificuldades iniciaram com até cinco anos de trabalho no setor, cinco entrevistados com até dez anos de trabalho e um entrevistado traz que as dificuldades iniciaram com onze anos de trabalho na agroindústria.

O período de início da manifestação das dificuldades em saúde relatado pela maioria dos trabalhadores participantes do estudo se assemelha ao que relata Buss (2010) que ao estudar trabalhadores dos frigoríficos atendidos no CEREST de Chapecó, evidencia que $83,4 \%$ destes manifestaram "sinais/sintomas" das LER/DORT antes de completarem cinco anos de trabalho. Na mesma direção, os estudos de Neli (2006) e Santos (2011), também mencionam a manifestação destas doenças ocupacionais nos trabalhadores do setor após períodos de trabalho semelhantes. $O$ curto espaço de tempo entre o exercício da atividade e a manifestação da dor, em vários dos casos estudados, indica a gravidade dos efeitos das condições de trabalho no setor na saúde dos trabalhadores.

A dor, com frequência, está associada à limitação e/ou à perda de movimentos dos membros atingidos, o que é citado por quatorze entrevistados. Nesse sentido os trabalhadores relatam especialmente dificuldades para realizar movimentos como erguer o braço, girar o pulso e caminhar. Como ilustra a fala da entrevistada 1: "Eu não consigo virar a mão assim, por exemplo, para torcer um pano ou então esfregar uma roupa", ou como diz a entrevistada 8: "eu mexo as panelas, faço alguma coisinha que dá com essa mão (mostra mão esquerda), porque eu fiquei um tempo que eu não podia nem escovar meus dentes, pentear 
meu cabelo, era o meu filho que fazia para mim, era estressante". A limitação e/ou perda dos movimentos indica a cronicidade do problema de saúde e afeta tanto a vida fora da fábrica quanto o desempenho laboral na linha de produção. Nesse sentido, foi possível observar que com frequência esses danos precedem as tentativas de mudança de função e os afastamentos do trabalho.

As alterações do sono citadas por seis trabalhadores são caracterizadas pela insônia, em que os entrevistados mencionam aspectos como dificuldade para pegar no sono, acordar precocemente e/ou acordar no meio da noite com dificuldade para voltar a conciliar o sono. Isso é ilustrado pela fala da entrevistada 7, que diz:

"De noite eu perco o sono e pra dormir amortecem os braços, aí eu deito de um lado amortece, deito de outro amortece. Hoje de manhã eu acordei eram $6 \mathrm{~h} 55 \mathrm{~m}$, eu chego em casa dez pra uma, quinze pra uma e se eu chegasse e já dormisse, mas daí tu deita e amortece, gela até o coro da cabeça daí demoro para dormir e de manhã qualquer barulho eu acordo".

Essas queixas apareceram relacionadas ao trabalho em turno noturno e à dor. De acordo com Seligmann-Silva (2011) “[...] uma acentuação dos distúrbios do sono costuma marcar tanto o agravamento da fadiga patológica quanto a transição entre esta e a configuração de quadros psicopatológicos típicos e, inclusive, de crises mentais agudas".

As dificuldades em relação ao tempo e qualidade do sono dos sujeitos que trabalham em turno noturno são mencionadas por Sato e Lacaz (2000), que associam esse horário de trabalho com o aparecimento de enfermidades gastrintestinais e problemas emocionais como ansiedade e depressão. Nesse sentido, um médico do CIS menciona: "Muitos trabalhadores da agroindústria vêm com quadros depressivos, mas a gente sabe que isso tem relação com eles trabalharem a noite, então eles não conseguem dormir direito, não têm uma boa qualidade de sono" (Notas diário de campo).

Outras queixas físicas mencionadas são também o inchaço e perda de força dos membros atingidos, aumento de peso e as parestesias. Essas se referem às alterações nas sensações cutâneas que no caso dos trabalhadores são em regiões do corpo específicas, sendo as mais recorrentes o frio, queimação e formigamento. As dores osteomusculares, especialmente nos membros superiores, associadas às parestesias comumente descritas pelos entrevistados, são consideradas preditoras das Lesões por Esforços Repetivivos comumente denominadas de LER/DORT como apontam Assunção e Vilela (2009).

Das queixas psicológicas, a mais frequente é a irritabilidade, a qual é mencionada por dez trabalhadores entrevistados e aparece associada ao quadro geral de saúde. A irritabilidade é descritas pelos trabalhadores usuários por meio de expressões como irritação, nervosismo, estresse, ou agressividade e, com frequência provoca conflitos familiares como expressa a trabalhadora 13:

"eu estressei muito meus filhos e meu marido. Nossa senhora, eu acho que várias vezes eles pensaram em não viver mais comigo, porque têm dias e horas que eu percebo que eu estou passada, que nem eu viveria comigo. Fico nervosa e daí eu falo qualquer besteira, eu xingo, é tudo normal". 


\section{Ou como menciona a entrevistada 7:}

"eu ando assim que qualquer coisinha pra mim é um bicho de sete cabeças, qualquer coisinha que me contrariam, tem que ser do meu jeito, tudo do meu jeito, estou assim, muito estressada sabe, e não é por aí, eu sei que não".

Em outros casos a irritabilidade está claramente associada ao desconforto físico provocado pela dor, como menciona a trabalhadora 4:

"Eu me irrito bastante, quando eu estou atacada do braço, daí parece que você não está confortável, a gente se sente incomodado, daí você vai fazer alguma coisa começa a doer, daí qualquer coisa te irrita, com dor é mais difícil de enfrentar tudo".

A ansiedade também é uma queixa psicológica recorrente, sendo é citada por seis entrevistados, os quais com frequência utilizam esse termo para descrever situações de inquietação, agitação, as quais são comumente acompanhadas de sensações físicas como falta de ar, aperto no peito. A fala do entrevistado 15 ilustra essa queixa:

\footnotetext{
"às vezes sentia uma coisa ruim aqui sabe, tipo uma ansiedade de trabalhar no fechado, tinha horas que dava vontade de voar lá dentro, só de você pensar em entrar lá [...], já estava difícil pra mim. Às vezes acontece de eu ficar bem ruim também dentro de casa, dormir de noite eu durmo bem, mas parece que eu estou lá na empresa, como se eu estivesse fechado lá, daí parece que falta o ar, que o coração acelera".
}

Queixas em relação ao sentimento de tristeza foram mencionadas por sete entrevistados, sendo que essas se deram em torno da descrição de dois ou mais sentimentos, como desânimo, falta de vontade de fazer as coisas, falta de vontade de viver, choro sem motivo aparente, baixa autoestima, sentimentos que os trabalhadores geralmente nomeavam como depressão. A fala da entrevistada 7 ilustra essa queixa quando diz:

"Eu não sei se é uma depressão ou o que, mas eu sinto um desânimo, um desânimo, ando sem vontade de fazer nada [...]. Aí parece que ninguém gosta de mim, sabe, parece que se eu ficasse aqui mais sozinha é melhor, sei lá por que (choro). Daí tem uma mulher que trabalha lá na empresa que também tem problema nos braços e ela disse, não sei se ela foi à psicóloga ou ao psiquiatra, mas ela disse que está bem melhor, que às vezes são coisas da cabeça da pessoa, mas eu tento esquecer a dor, mas não adianta, não passa".

Levando em consideração as queixas psicológicas apresentadas, destacamos que de acordo com Henriques et al (2015) frequentemente a dor crônica está associada a sintomas depressivos e ansiedade. Ainda de acordo com os autores, a maioria dos estudos sugerem que "[...] a dor crônica costuma preceder a depressão e suceder a dependência química e os transtornos de ansiedade" ( $p$. 694). entrevistados. Esse medo foi mencionado somente por aqueles entrevistados 
que estavam afastados do trabalho pela previdência social em função de incapacidade laboral. Em torno dessa queixa os entrevistados citavam a possibilidade de perder o emprego no retorno ao trabalho, bem como a dificuldade que teriam em se inserir em outra atividade ocupacional diante do adoecimento.

Na direção do que é apontado, a trabalhadora 2 menciona:

“eu fui, mês passado lá na empresa, só de entrar lá já vai me dando uma coisa ruim, uma ansiedade ruim, pensar que se eles me liberarem, tenho que voltar lá todo dia, encarar aquele trecho de novo, não sei se vou conseguir, [...] e eles vão me mandar embora, é só vencer a estabilidade, depois eles me mandam embora [...] e já pensou, eu vou ter que dar um jeito de sobreviver, só com o salário do meu marido a gente não vai conseguir dar a volta, e qual a empresa que vai me pegar com o problema que eu tenho? Não tem empresa que me pegue. Eu tenho medo por causa disso".

Já no que diz respeito às queixas sociais, a principal delas é em relação à limitação no exercício das atividades cotidianas, a qual é citada por nove trabalhadores entrevistados e está relacionada à perda e à limitação de movimentos do corpo. De modo geral esta queixa implica a perda de autonomia do trabalhador e a dependência dos familiares para realizar atividades que antes realizavam. Em algumas situações essas limitações passam a ser objeto de conflitos familiares. Nesse sentido, o entrevistado 17 menciona:

"Aí a mulher chega em casa do serviço, daí o cara gostaria de ajudar, mas vai ajudar de que jeito? Então fica pesado pra ela, daí mesmo sem querer, ela te olha e fala alguma coisa, e de repente aquilo lá, ela pensa que não te ofende e te ofende, e eu não sou uma pessoa assim de desabafar, acho que um pouco é isso, eu me guardo pra mim, eu fico martelando, é complicado" (Trabalhador 17).

Outra queixa social mencionada por seis trabalhadores foi não poder trocar de emprego devido ao problema de saúde. Nesse sentido, os entrevistados se sentem presos ao trabalho na agroindústria pela necessidade de manter a renda e por entenderem que não têm possibilidade de conseguir outro trabalho ante o adoecimento. Como diz a Trabalhadora 7:

“Meu marido não quer mais que eu fique lá, mas se eu sair de lá eu vou fazer o que da vida com problema nos braços, e a gente tem que trabalhar. A gente também sem estudo vai fazer o que? E daí eu não tenho força nos braços, eu não consigo mais outro trabalho".

O isolamento social, por sua vez, é uma queixa que aparece na fala dos trabalhadores que estão afastados da atividade e que por isso se distanciaram da rede social de apoio que tinham no trabalho. Esse isolamento ocorre também devido à dor e ao sentimento de tristeza que geram a perda de vontade de sair de casa, bem como de realizar outras atividades. A dor crônica é:

[...] uma experiência solitária, que não pode ser compartilhada com terceiros. Essa situação tem um profundo impacto na vida laboral, social e familiar do indivíduo. Isolamento e conflitos são comuns com essas mudanças, influenciando de modo negativo na 
capacidade da construção de relacionamentos e envolvimento em situações gratificantes. Tais fatores são cruciais na perda de qualidade de vida dos pacientes(HENRIQUESet al, 2015).

Se realizada uma leitura horizontal do quadro anterior, tomando as diferentes queixas de um mesmo trabalhador, é possível observar que essas se influenciam e condicionam mutuamente, só podendo ser compreendidas na inter-relação que estabelecem. Nesse sentido, tomando o caso da trabalhadora 2, observa-se esta reciprocidade entre as queixas, quando ela diz:

"Doía bastante à noite e agora não é mais só à noite, é de dia também, dá formigamento nas mãos, comecei a perder os movimentos, daí esfregar uma panela não tenho mais força, esfregar um fogão não tenho força, porque começar a esfregar dá aquele choque sabe, tu perde os movimentos, às vezes eu estou segurando alguma coisa e simplesmente ela cai da minha mão".

Na sequência a mesma trabalhadora relata como a dor, a perda e limitação de movimentos, e a limitação no exercício das atividades cotidianas se relacionam com outras dificuldades psicológicas e sociais:

"Sabe, eu não estou muito legal ultimamente (choro), o meu marido disse que eu estou com depressão, é que qualquer coisinha eu estou chorando. (Entrevistadora) Porque você acha que está se sentindo assim? (Entrevistada) Olha, o maior prazer para mim era chegar em casa e ajeitar minha casa, deixar tudo limpinho, organizado (choro), agora me dói ver as minhas coisas jogadas porque eu não consigo mais fazer, e também eu não posso cobrar deles, a minha menina e ele trabalham o dia todo. E essa maldita dor, ela me incomoda, não dá descanso" (Trabalhadora 2).

A fala da entrevistada 5 também elucida como as diferentes queixas fundemse ao longo da descrição da dificuldade.

"Eu estou comendo que nem uma vaca, nem fome eu tenho e até vomitar eu vomito. Não é que eu queira comer, é uma ansiedade que eu não sei de onde vem, daí eu acabo comendo. Desde que eu me afastei da empresa já engordei 18 quilos. E daí muito nervosa por nada, eu fico brava, meu marido diz que eu tenho que me controlar, mas eu não consigo, parece que eu tenho que por pra fora, daí depois eu me arrependo, de uma onça viro um gatinho".

Os relatos mostram como as queixas físicas de dor, perda e limitação dos movimentos, aumento de peso, estão relacionadas às queixas psicológicas de ansiedade, irritabilidade, sensação de tristeza, e às queixas sociais de limitação no exercício das atividades cotidianas e conflitos familiares. Este panorama das queixas em saúde deve auxiliar a compreender quais destas queixas chegam aos serviços de saúde, sendo alvo de práticas assistenciais, que práticas são essas e como elas influenciam na condição de saúde desses trabalhadores usuários. 


\section{DIAGNÓSTICO EM SAÚDE RELACIONADAS AO TRABALHO}

Os trabalhadores das agroindústrias que participaram deste estudo eram aqueles que de alguma maneira figuravam para os profissionais da Atenção Básica e para outros trabalhadores por terem queixas em saúde relacionadas à sua atividade laboral. Assim, todos os entrevistados faziam uso esporádico ou contínuo de serviços de saúde em função dos problemas que apresentavam. Este uso dos diferentes serviços, públicos e privados, permitem traçar os percursos destes trabalhadores pela rede de saúde.

No percurso dos trabalhadores entrevistados pelos serviços de saúde foram produzidos diferentes registros técnicos, os quais, além de orientar as ações assistenciais, também são indicadores de saúde do trabalhador, como afirma o Manual de Procedimentos para os Serviços de Saúde (BRASIL/OPAS, 2001), constituindo-se em uma importante fonte de informações para subsidiar os processos de planejamento, gestão e avaliação das políticas públicas nesse campo. Essas informações também acenam para os riscos da atividade do setor $\mathrm{e}$ auxiliam a compreender as intervenções que se produzem na rede de saúde em relação aos problemas apresentados.

Nesse sentido, o quadro com as informações a seguir foi construído a partir das entrevistas, prontuários de saúde do CIS e dos documentos que os trabalhadores apresentavam durante as entrevistas, como exames, atestados médicos, registros da previdência social entre outros. 
Quadro 2: Informações sobre o percurso dos trabalhadores pela rede de saúde

\begin{tabular}{|c|c|c|c|c|c|c|}
\hline \multirow[t]{2}{*}{ No } & \multirow[t]{2}{*}{ Condição atual } & \multirow{2}{*}{$\begin{array}{l}\text { Recebimento } \\
\text { de auxílio } \\
\text { doença } \\
\text { anterior }\end{array}$} & \multirow{2}{*}{$\begin{array}{l}\text { Tempo de duração do } \\
\text { afastamento atual }\end{array}$} & \multicolumn{3}{|c|}{ Diagnósticos } \\
\hline & & & & $\mathbf{F}^{1}$ & $\begin{array}{l}\text { G } \\
2\end{array}$ & $M^{3}$ \\
\hline 01 & Trabalhando & Não & - & & & $x$ \\
\hline 02 & $\begin{array}{l}\text { Em auxílio- } \\
\text { doença } \\
\text { acidentário }\end{array}$ & Não & 10 meses & & & $X$ \\
\hline 03 & $\begin{array}{c}\text { Em auxílio- } \\
\text { doença }\end{array}$ & Não & 3 anos & & & $X$ \\
\hline 04 & $\begin{array}{c}\text { Em auxílio- } \\
\text { doença }\end{array}$ & Não & 3 meses & & & $x$ \\
\hline 05 & $\begin{array}{l}\text { Em auxílio- } \\
\text { doença } \\
\text { acidentário }\end{array}$ & Não & 3 anos & & $\mathrm{X}$ & $X$ \\
\hline 06 & $\begin{array}{l}\text { Em auxílio- } \\
\text { doença* }\end{array}$ & Não & - & $x$ & & \\
\hline 07 & Trabalhando & Sim & - & & & $X$ \\
\hline 08 & $\begin{array}{l}\text { Em auxílio- } \\
\text { doença } \\
\text { acidentário }\end{array}$ & Sim & 1 ano e 9 meses & $x$ & & $X$ \\
\hline 09 & $\begin{array}{c}\text { Em auxílio- } \\
\text { doença }\end{array}$ & Não & 4 anos e 6 meses & $x$ & & \\
\hline 10 & Trabalhando & Sim & - & & & $\mathrm{X}$ \\
\hline 11 & $\begin{array}{l}\text { Em auxílio- } \\
\text { doença } \\
\text { acidentário }\end{array}$ & Não & 1 ano e 7 meses & & & $X$ \\
\hline 12 & $\begin{array}{l}\text { Em auxílio- } \\
\text { doença } \\
\text { acidentário }\end{array}$ & Não & 1 mês & & & $x$ \\
\hline 13 & $\begin{array}{c}\text { Em auxílio- } \\
\text { doença }\end{array}$ & Sim & 3 meses & $x$ & & $X$ \\
\hline 14 & Trabalhando & Não & - & & & $\mathrm{X}$ \\
\hline 15 & $\begin{array}{c}\text { Em auxílio- } \\
\text { doença }\end{array}$ & Não & 7 meses & & & $X$ \\
\hline 16 & $\begin{array}{l}\text { Em auxílio- } \\
\text { doença } \\
\text { acidentário }\end{array}$ & Sim & 3 meses & & & $X$ \\
\hline 17 & $\begin{array}{c}\text { Em auxílio- } \\
\text { doença }\end{array}$ & Sim & 3 anos & & & $X$ \\
\hline
\end{tabular}

1 Transtornos mentais e comportamentais (F00-F99 do CID-10).

2 Doenças do sistema osteomuscular e do tecido conjuntivo (M00-M99 do CID-10).

3 Doenças do sistema nervoso (G00-G99 do CID-10).

* Foram afastados durante a realização da pesquisa. 
Quando os profissionais de saúde relacionam a situação/queixa do trabalhador usuário a uma doença reconhecida, produz-se um diagnóstico, o qual é frequentemente representado por meio do sistema de Classificação Estatística Internacional de Doenças e Problemas Relacionados à Saúde (CID-10). Esses diagnósticos orientam as práticas assistenciais, o percurso dos trabalhadores pela rede de saúde e as ações no campo dos direitos trabalhistas.

Como podemos observar no quadro anterior, os diagnósticos recebidos pelos trabalhadores entrevistados neste estudo estão localizados em três grupos do CID-10, sendo eles: o grupo $F$, no qual se descrevem os transtornos mentais e comportamentais, o grupo $M$, que diz respeito às doenças do sistema osteomuscular e do tecido conjuntivo e o grupo $\mathrm{G}$, que representa as doenças do sistema nervoso. Cabe destacar que as doenças do grupo $\mathrm{M}$ e $\mathrm{F}$ tem sido respectivamente a primeira e terceira principal causa de concessão de auxílios doença pela Previdência Social nos últimos anos (MINISTÉRIO DO TRABALHO E PREVIDÊNCIA SOCIAL, 2014)

No quadro acima se observa que, dos dezessete trabalhadores usuários participantes do estudo, quinze têm diagnósticos de doenças do sistema osteomuscular e do tecido conjuntivo (grupo M do CID-10), sendo esse o diagnóstico predominante. Um dos trabalhadores (5), além do diagnóstico do grupo $\mathrm{M}$, tem também o diagnóstico de doença do sistema nervoso (grupo $\mathrm{G}$ ) e dois (8 e 13) têm também diagnóstico de transtorno mental e comportamental (grupo F). Como se pode observar há dois trabalhadores (6 e 9) que têm somente diagnósticos do grupo F.

Os diagnósticos recebidos por esse grupo de trabalhadores, bem como as queixas por eles trazidas, caracterizam a forte presença das LER/DORT nesta categoria. Essas informações vão ao encontro do que se observou nas notificações em agravos à saúde do trabalhador, obtidas junto ao CEREST de Chapecó. As mesmas evidenciaram que no período de 2008 a 2010 foram realizada cinquenta e oito notificações de agravos dos trabalhadores das agroindústrias da região, das quais quarenta e quatro receberam diagnósticos do grupo M do CID-10. Entre esses diagnósticos, os mais frequentes (vinte e dois casos) foram de Sinovite/Tenossinovite e Síndrome do Manguito Rotador, ambas comumente descritas entre as LER/DORT.

A prevalência das LER/DORT nos trabalhadores das indústrias de alimentos da região estudada, também é mencionada no estudo de Sardá, Ruiz e Kirtschig (2009) acerca dos dados do INSS de Chapecó referentes ao período de 2004 a 2008. Esses dados indicam que os diagnósticos realizados na avaliação pericial de trabalhadores vinculados a duas agroindústrias do setor, concentravam-se nos grupos M, F e G do CID-10. Nesse sentido, nos 2.983 afastamentos do trabalho, 833 trabalhadores (28\%), receberam diagnósticos do grupo M, 624 trabalhadores (21\%) receberam diagnósticos do grupo F e 1.526 (51\%) tiveram diagnosticadas doenças dos grupos F, G e M.

A condição atual dos trabalhadores indica o afastamento ou não do trabalho por incapacidade laboral devido aos problemas de saúde. Nesse sentido, podemos observar no quadro anterior que treze dos dezessete usuários entrevistados estavam afastados do trabalho recebendo auxílio-doença, sendo que a um desses trabalhadores o benefício foi concedido após a realização da entrevista, enquanto a pesquisa de campo ainda estava em curso. Em relação aos 
quatro entrevistados que estavam trabalhando, dois deles mencionaram que já haviam recebido auxílio-doença anteriormente, o que evidencia que somente dois trabalhadores entrevistados nunca foram afastados do trabalho por incapacidade laboral. Cabe apontar ainda, que três dos trabalhadores que estavam afastados do trabalho no momento da pesquisa recebiam o auxíliodoença pela segunda vez, considerando-se apenas o período em que esses mantinham vínculo de emprego com as agroindústrias.

Em relação ao tempo de afastamento do trabalho, pode ser observado no quadro anterior que este variava de um mínimo de mês ${ }^{2} a$ um máximo de quatro anos e meio. Assim, seis trabalhadores estavam afastados do trabalho recebendo auxílio-doença há até um ano, dois trabalhadores estavam afastados há mais de um ano e meio, três trabalhadores há três anos e um trabalhador estava em auxílio doença a mais de quatro anos.

A presença de trabalhadores do setor em auxílio-doença vinculados ao CIS em que foi realizado o estudo também se apresentou no mapeamento de trabalhadores usuários para realizar a entrevista, junto às agentes de saúde de duas microáreas do CIS. Nesse sentido, além dos dezessete trabalhadores entrevistados, foram identificados mais vinte e seis trabalhadores do setor afastados do trabalho recebendo auxílio doença, dos quais sete com diagnóstico de depressão e dezenove por LER/DORT, o que corrobora com as informações descritas anteriormente.

Em relação aos auxílios-doença concedidos, os auxílios-doença acidentários são aqueles em que é reconhecido o nexo causal ou técnico entre a atividade laboral e a doença. No quadro 3 se observa que dos catorze auxílios-doença concedidos, apenas seis trabalhadores receberam auxílio-doença acidentário. Chama a atenção ainda que entre os oito trabalhadores usuários que estavam afastados do trabalho sem o reconhecimento do nexo técnico, estão os três casos (6, 9 e 13) cujo afastamento ocorreu pelo diagnóstico inicial de transtornos mentais e comportamentais. No outro caso que recebeu o diagnóstico do grupo $\mathrm{F}$ (usuário 8), esse não foi a causa do afastamento, sendo considerado um quadro secundário ao quadro de LER/DORT. Cabe destacar ainda que no caso da trabalhadora usuária 3, em que não é estabelecido o nexo, ela foi afastada do trabalho após sofrer um acidente doméstico, apesar de esta apresentar um quadro de LER/DORT anterior ao acidente.

Estabelecer a relação entre o trabalho e os processos de saúde-doença da população segundo documento sobre doenças relacionadas ao trabalho é a condição básica para implementação das ações no campo da Saúde do Trabalhador(BRASIL/OPAS, 2001). Nesse sentido, o reconhecimento do caráter acidentário dos agravos em saúde do trabalhador possibilita a geração de indicadores epidemiológicos que devem nortear as políticas de prevenção e as ações de vigilância, bem como define questões do ponto de vista previdenciário e trabalhista (MINISTÉRIO DO TRABALHO E EMPREGO, 2008). Esse reconhecimento traz, assim, implicações éticas, técnicas, e legais que envolvem organizações, serviço de saúde e trabalhadores, os quais influenciam deforma importante a atenção à saúde dos trabalhadores.

${ }^{2}$ Não está sendo considerado aqui o trabalhador que foi afastado depois da realização da entrevista. 


\section{CONSIDERAÇÕES FINAIS}

O fenômeno do adoecimento do trabalhador nas indústrias de abate e processamento de carnes vem se agravando nas últimas décadas, apesar da modernização tecnológica e da organização dentro do processo de restruturação produtiva.Isso indica que os trabalhadores continuam sendo submetidos a condições de trabalho extremamente degradantes. Este fenômeno deve-se principalmente à intensificação do ritmo de trabalho através do mecanismo de coerção psicológica e organizacional referente à subordinação do homem ao capital. Diante destas informações este artigo teve como objetivo compreender as principais queixas e diagnósticos em saúde dos trabalhadores das indústrias de abate e processamento de carnes do oeste do estado de Santa Catarina.

Em relação às queixas em saúde, estas foram classificadas em queixas físicas, queixas psicológicas e queixas sociais, as quais não podem ser analisadas separadamente já que se implicam e condicionam reciprocamente. Entre estas destacaram-se a dor, irritabilidade, ansiedade, alterações no sono, limitação na realização de atividades cotidianas e isolamento social. Apesar das singularidades que distinguem um caso de outro, é possível observar uma grande semelhança entre as queixas dos diferentes trabalhadores usuários, o que indica a sua origem comum, que é o trabalho.

Estas queixas, quanto chegam aos serviços de saúde, são rotuladas por meio de diagnósticos que acompanham estes trabalhadores ao longo do seu percurso no processo de adoecimento. Os principais diagnósticos recebidos são às doenças do sistema osteomuscular e do tecido conjuntivo (Grupo M do CID-10), as doenças do sistema nervoso (Grupo G do CID-10), e os transtornos mentais e comportamentais (Grupo $\mathrm{F}$ do CID-10). Estes diagnósticos, quando adequadamente relacionados ao trabalho evidenciam a forte presença das LER/DORT nos trabalhadores do setor, característica esta que vem ao encontro dos estudos já existentes nos trabalhadores das indústrias de alimentos.

Este panorama das queixas em saúde deve auxiliar a compreender quais destas queixas chegam aos serviços de saúde, sendo alvo de práticas assistenciais, que práticas são essas e como elas influenciam na condição de saúde desses trabalhadores usuários. 


\title{
Complaints and diagnostic related to work in agribusinesses at west of Santa Catarina - Brazil
}

\begin{abstract}
Slaughter and processing industries of meat from the west region of Santa Catarina state are important for the Brazilian economic sector, especially in the production and export of poultry meat. The municipality of Chapecó occupies a prominent place in this context, since is considered one of the largest agribusinesses centers of the country, with approximately $18 \%$ of the workforce employed in this sector. However, it is important to note that there is difficult working conditions in these industries that are widely associated with health, such as Repetitive Strain Injury (RSI). This paper aims to understand the main health complaints and diagnoses of workers from slaughter and processing industries of meat from the west of Santa Catarina state- Brazil. The investigative process happened from the qualitative research and using different instruments: participant observation; semi-structured interviews and documentary research. The analysis of the information was based on Grounded Theory. The results met complaints related to the physical, psychological and social work. With respect to incoming diagnostics, these are primarily of the group $F$, which describes the mental and behavioral disorders, the group $M$, which relates to musculoskeletal system and conjunctive tissue diseases and the group $G$, which represents the nervous system diseases.
\end{abstract}

KEYWORDS: Worker health. Health complaints. RSI/WMSD. Agribusinesses. 


\section{REFERÊNCIAS}

AMAZARRAY, M. R.; CÂMARA, S. G.; CARLOTTO, M. S. Investigação em saúde mental e trabalho no âmbito da saúde pública no Brasil. In. MERLO, A.; BOTTEGA, C. ; PEREZ, K. (Orgs). Atenção à saúde mental do trabalhador: sofrimento e transtornos psíquicos relacionados ao trabalho. (pp. 75-92). Porto Alegre: Evangraf, 2014.

ASSUNÇÃO, A. A.; VILELA, L. V. O. Lesões por esforços repetitivos: Guia para profissionais de saúde. Piracicaba: Centro de Referência em Saúde do trabalhador- CEREST.2009. Disponível em: $<$ http://bvsms.saude.gov.br/bvs/publicacoes/livro ler guia profissional 1.p df>. Acesso em:13/04/2016.

BRASIL. HumanizaSUS. Acolhimento com avaliação e classificação de risco: um paradigma ético-estético no fazer em saúde. Brasília: Ministério da Saúde. 2004a.Disponível em: $<$ http://bvsms.saude.gov.br/bvs/publicacoes/acolhimento.pdf>. Acesso em: 13/04/2016.

BRASIL. HumanizaSUS. Política Nacional de Humanização: a humanização como eixo norteador das práticas de atenção e gestão em todas as instâncias do SUS. Brasília: Ministério da Saúde. 2004b. Disponível em:<http://bvsms.saude.gov.br/bvs/publicacoes/humanizasus 2004.pdf $>$. Acesso em: 13/04/2016.

BRASIL. Cartilha da PNH: clínica ampliada. Brasília: Ministério da Saúde. 2008b. Disponível em: $\leq$ http://bvsms.saude.gov.br/bvs/publicacoes/clinica ampliada.pdf $>$. Acesso em: 13/04/2016.

BRASIL. Acolhimento e classificação de risco nos serviços de urgência. Brasília: Ministério da Saúde, 2009. Disponível em: $<$ http://bvsms.saude.gov.br/bvs/publicacoes/acolhimento classificaao risco servico urgencia.pdf>. Acesso em: 13/04/2016.

BRASIL. Ministério da Saúde. Portaria no 1.823, de 23 de agosto de 2012. Institui Política Nacional de Saúde do Trabalhador e da Trabalhadora. Ministério da Saúde, 2012. Disponível em: <http://bvsms.saude.gov.br/bvs/saudelegis/gm/2012/prt1823 2308 2012.html >. Acesso em: 17/03/2016. 
lina\%20Doencas\%20do\%20Trabalho/Manual\%20DO\%20Min\%20Saude.pdf>. Acesso em: 20/04/2016.

BUSS, D. C. Perfil dos trabalhadores de empresas frigoríficas portadores de lesões por esforços repetitivos osteomusculares relacionados ao trabalho atendidos no Centro de Referência em Saúde do Trabalhador de Chapecó no ano de 2008. Monografia (Curso de Especialização em Saúde do Trabalhador). Escola de Saúde Pública Professor Mestre Osvaldo de Oliveira Maciel, Florianópolis, 2010.

DAL MAGRO, M. L. P. Entre a saúde e a norma: a atenção à saúde dos trabalhadores das agroindústrias do oeste de Santa Catarina. Tese de doutorado apresentada ao Programa de Pós-Graduação em Psicologia da Universidade Federal de Santa Catarina, 2012.

DAL MAGRO, M. L. P.; COUTINHO, M. C.; MORÉ, C. L. O. O obscurecimento da dor coo dispositivo de controle da força de trabalho frente às LER/DORT: o caso das indústrias de abate e processamento de carnes. UniversitasPhychologica. v. 12, n. 4., p. 1195-1209, 2013. Disponível em:<http://revistas.javeriana.edu.co/index.php/revPsycho/article/view/6497>. Acesso em: 03/07/2016.

DAL MAGRO, M. L. P.; COUTINHO, M. C.; BLANCH, J. M.; MORÉ, C. L. O. Intensificação e prolongamento da jornada de trabalho nas indústrias de abate e processamento de carnes e seus impactos na saúde dos trabalhadores. Cadernos de Psicologia Social e do Trabalho. v. 17, n. 1., p. 67-83, 2014. Disponível em: $<$ http://pepsic.bvsalud.org/scielo.php?script=sci arttext\&pid=S151637172014000200006>. Acesso em: 03/07/2016.

DAL MAGRO, M. L. P.; COUTINHO, M. C.; MORÉ, C. L. O. Relações de poder na atenção à saúde do trabalhador formal: o caso da indústria de abate e processamento de carnes. Revista Brasileira de Saúde Ocupacional. (No prelo). DOI: 10.1590/0303-7657000100314

DALLA COSTA, A. D.; SOUZA-SANTOS, E. R.Brasil Foods: a fusão entre Perdigão e Sadia. Economia \& Tecnologia, v. 17, n. 5, p. 165-176, 2009.

IBGE. Tabela 14:Unidades locais, pessoal ocupado total e assalariado, salários e outras remunerações e salário médio mensal, segundo Municípiosde Santa Catarina com 50 mil ou mais habitantes e divisão da classificação de atividades - 2009. Dados fornecidos pelo IBGE de Chapecó em formato eletrônico. 2009. 
GREGORIM, C. O. Moderno Dicionário da Língua Portuguesa. São Paulo: Melhoramentos. 2007. Disponível em: $<$ http://michaelis.uol.com.br/moderno/portugues/index.php?typePag=credit os\&languageText=portugues-portugues $>$. Acesso em: 13/04/2012.

HENRIQUES, A.; CALEFFI, L.; SCHESTATSKY, P.; AGUIAR, R. W. Abordagem psicodinâmica do paciente com dor crônica. In. C. L. EIZIRIK; R. W. AGUIAR; S. S. SCHESTATSKY (Orgs.). Psicoterapia de orientação analítica: fundamentos teóricos e clínicos (pp. 689-703). 3 ed. Porto Alegre: Artmed, 2015.

MACHADO, J.; SORATTO, L.; CODO, W (Orgs). Saúde e trabalho no Brasil: uma revolução silenciosa: o Ntep e a Previdência Social. Petrópolis: Vozes, 2010.

MINISTÉRIO DO TRABALHO E EMPREGO - MTE.Anuário Estatístico de Acidentes do Trabalho : AEAT 2007. Ministério doTrabalho e Emprego [et al.]. - vol. 1 . Brasília : MTE :MPS. 2008.

MINISTÉRIO DO TRABALHO E EMPREGO. NR-36 - Segurança e saúde no trabalho em empresas de abate e processamento de carnes e derivados. Portaria MTE $n$. 555, de 18 de abril de 2013. Brasília: Ministério do Trabalho e Emprego, 2013.

MINISTÉRIO DO TRABALHO E EMPREGO - MTE. Anuário Estatístico de Acidentes do Trabalho: AEAT 2014. Ministério doTrabalho e Emprego [et al.]. - Brasília : MTE :MPS.

AEPS - Anuário Estatístico da Previdência Social 2014. Ministério do Trabalho e Previdência Social, Empresa de Tecnologia e Informações da Previdência SocialBrasília : MTPS/DATAPREV, 2014.

NELI, M. A. Reestruturação produtiva e saúde do trabalhador: um estudo com os trabalhadores de uma indústria avícola. Dissertação (Mestrado em Ciências Médicas) Programa de Pós-Graduação em Ciências Médicas, Universidade de São Paulo, Ribeirão Preto, 2006. Disponível em:<http://www.teses.usp.br/teses/disponiveis/17/17139/tde-18092006154325/pt-br.php>. Acesso em: 13 /04/ 2016.

PROCURADORIA REGIONAL DO TRABALHO NO ESTADO DE SANTA CATARINA. 2013. Notícia publicada em 03/12/2013. Disponível em: <http://www.prt12.mpt.mp.br/prt/noticias/2013 12/03 12.php >. Acesso em: 09/12/2015. 
Coloquio Internacional de Geocrítica - Diezaños de cambiosenel Mundo, enlaGeografía y enlasCienciasSociales 1999-2008, Barcelona: Universidad de Barcelona, 2008.

SANTOS, M. A. O sofrimento dos Trabalhadores da Agroindústria Sadia S.A. de Chapecó. Dissertação de Mestrado em Serviço Social, Programa de PósGraduação em Serviço Social, Universidade Federal de Santa Catarina, Florianópolis, 2011.

SARDÁ JÚNIOR, J. J. KUPEK, E.; CRUZ, R.. Preditores biopsicossociais de incapacidade física e depressão em trabalhadores do setor de frigoríficos atendidos em um programa de reabilitação profissional. Acta Fisiátrica, v.16, n. 2, p. 76-80, 2009.

SATO, L.; LACAZ, F. A. C. Cadernos de Saúde do Trabalhador: condições de trabalho e saúde dos trabalhadores(as) do ramo da alimentação. São Paulo: Instituto Nacional de Saúde do Trabalhador, 2000.

SELIGMANN-SILVA, E. Trabalho e desgaste mental: o direito de ser dono de si mesmo. São Paulo: Cortez, 2011.

STRAUSS, A.; CORBIN, J. Pesquisa qualitativa: técnicas e procedimentos para o desenvolvimento de teoria fundamentada. ( 2 a ed.). Porto Alegre: Artmed. 2008.

Recebido: 08 abr. 2016

Aprovado: 03 jun. 2016.

DOI: $10.3895 /$ rbpd.v5n2.4492

Como citar: DAL MAGRO, M. L. P. et al. Queixas e diagnósticos relacionados ao trabalho em agroindústrias

do oeste de Santa Catarina - Brasil. R. bras. Planej. Desenv.,Curitiba, v. 5, n. 2, p. 198-218, mai./ago. 2016.

Disponível em: <https://periodicos.utfpr.edu.br/rbpd>. Acesso em: XXX.

Correspondência:

Márcia Luíza Pit Dal Magro

Av. Atílio Fontana, 591 - E - Efapi, Chapecó, SC.

Direito autoral: Este artigo está licenciado sob os termos da Licença CreativeCommons-Atribuição 4.0

Internacional. 